\title{
Nasal and Upper Lip Reconstruction of a Case of Squamous Cell Carcinoma Nose Stage IV-A Case Report
}

\author{
Medhat Emil Habib*, Mahaba Mamoun, Mazen Al-Samarrae, Christoph Reuter \\ Plastic \& Reconstructive Surgery Department, Mafraq Hospital, Abu Dhabi, United Arab of Emirates \\ Email: " medhatemil1@hotmail.com
}

Received 29 July 2014; revised 25 August 2014; accepted 15 September 2014

Copyright (C) 2014 by authors and Scientific Research Publishing Inc.

This work is licensed under the Creative Commons Attribution International License (CC BY). http://creativecommons.org/licenses/by/4.0/

c) (i) Open Access

\begin{abstract}
We report a case of 77 years old male patient who presented to our hospital with bleeding from a fungating mass of the nose. Investigations revealed the lesion to be moderately differentiated basaloid type squamous cell carcinoma, with lung, liver and spleen metastasis. Oncologists started palliative chemotherapy for the patient. Excision of the tumour required removal of most of the nose including the lateral nasal cartilages and the nasal septum. Nasal reconstruction was done by using left nasolabial flap after deepithelialising 3 parts of it and covering that flap with a forehead flap. Residual tumour of the upper lip required further excision later on and coverage with a fan flap. The patient survived about 6 months after the surgery in a good appearance and was accepted and approached well by his family. We think that this type of reconstruction is suitable for late stages cancer nose considering the life expectancy of this category of patients.
\end{abstract}

\section{Keywords}

Nasal Reconstruction, Nasolabial Flap, Forehead Flap, Fan Flap

\section{Introduction}

The site of the nose, being at the center of the face, makes any lesion in it well evident and noticeable. It is rare to get patients presenting to the clinic for the first time with a large fungating mass with bleeding. The bad smell of the cancer, the disfigurement, the haemorrhage from the tumour and the community avoidance are all factors that can push the patient to seek medical advice. The patient presented in this case was found to have stage IV squamous cell carcinoma with metastasis to internal organs. Considering the life expectancy of the patient, the

"Corresponding author.

How to cite this paper: Habib, M.E., Mamoun, M., Al-Samarrae, M. and Reuter, C. (2014) Nasal and Upper Lip Reconstruction of a Case of Squamous Cell Carcinoma Nose Stage IV-A Case Report. Modern Plastic Surgery, 4, 58-65.

http://dx.doi.org/10.4236/mps.2014.44011 
classical ways of nasal reconstruction incorporating cartilage grafts or other steps with possible additional complications were not preferred to be done. Nasal reconstruction was done in a way that could afford good shape of the nose and acceptance by the community.

\section{Case Report}

A 77 years old thin underweight gentleman presented to Mafraq Hospital Accident and Emergency Department for the first time with bleeding from a big fungating mass of his nose. According to the patient and his family, the lesion started as a small boil of one year duration and was progressively increasing in size. There was a history of recurrent attacks of bleeding from the mass. There was a history of productive cough. There was no history of treatment from debilitating diseases and no history of previous operations.

The general examination of the patient showed that his height is $148 \mathrm{~cm}$ and the weight is $37.5 \mathrm{Kg}$ with a body mass index of $17.1 \mathrm{Kg} / \mathrm{m}^{2}$.

The local examination showed a bad odour fungating mass of a size $5.5 \times 5 \times 3.5 \mathrm{~cm}$ occupying the tip of the nose, dorsum, columella and lateral nasal cartilages. The mass had raised everted edges with irregular surface and mild bleeding from it. There was no epistaxis. No lymph nodes were palpable in the neck (Figure 1).

$\mathrm{X}$-ray chest done showed a superior mediastinal mass with haziness in the left upper zone.

This was confirmed by the CT scan which showed large malignant mass lesion in left lung, consistent causing left upper lobe collapse with infiltration of left pulmonary artery and aorta. There were mediastinal nodal metastasis and multiple hepatic and splenic metastasis (Figure 2(a) and Figure 2(b)).

Facial CT scan showed enhancing ulcerated soft tissue density mass lesion arising from the nose and anterior nares. The mass was found infiltrating the anterior portion of the cartilaginous nasal septum. There was no evidence of infiltration of the nasal bones or the paranasal sinuses with no intracranial extension of the mass (Figure 2(c) and Figure 2(d)).

Liver image guided core biopsy was done and showed metastatic sinonasal squamous cell carcinoma, basaloid type.
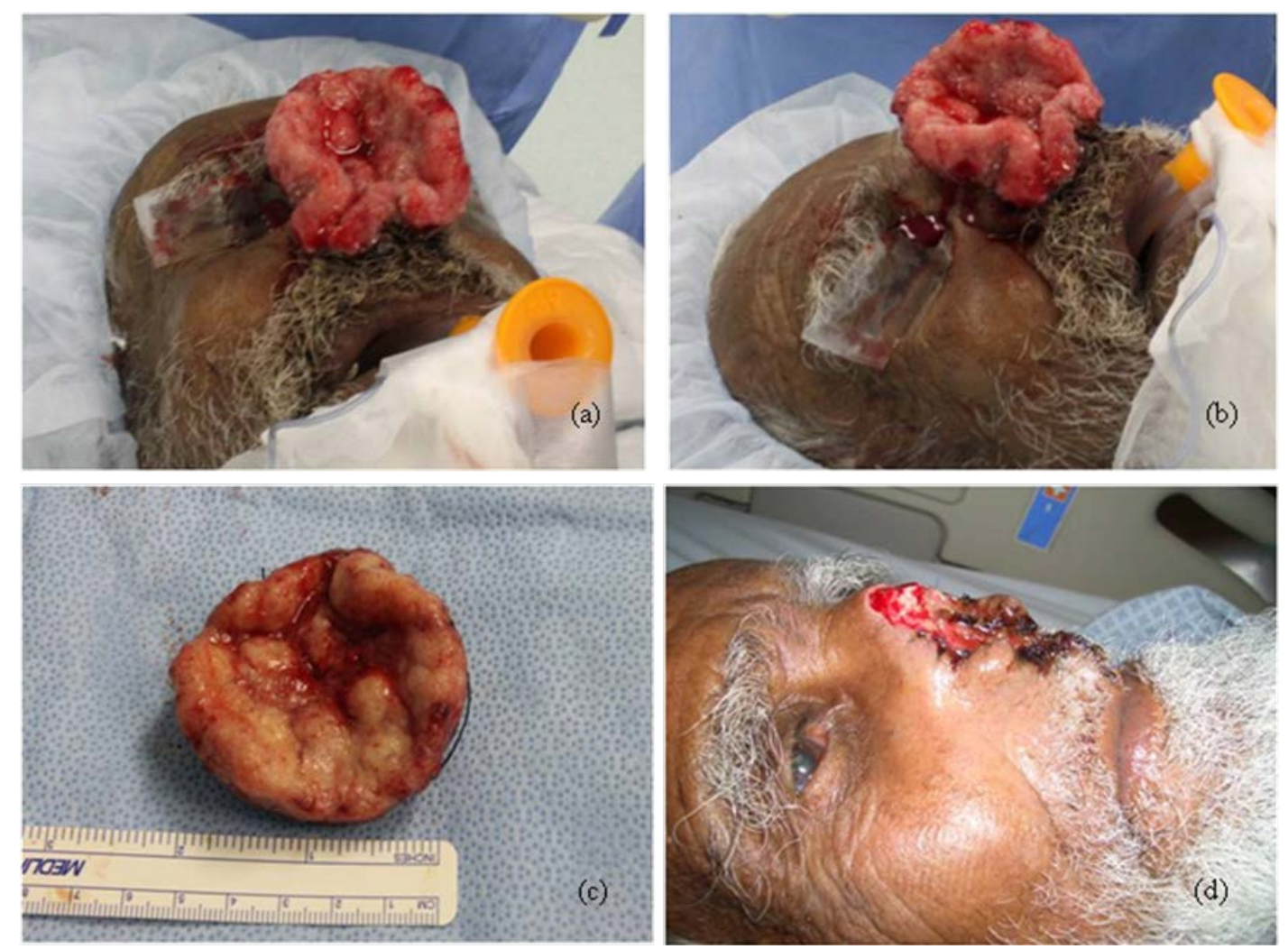

Figure 1. (a) (b) Two views of the fungating mass; (c) Size of the mass after excision; (d) Residual defect. 

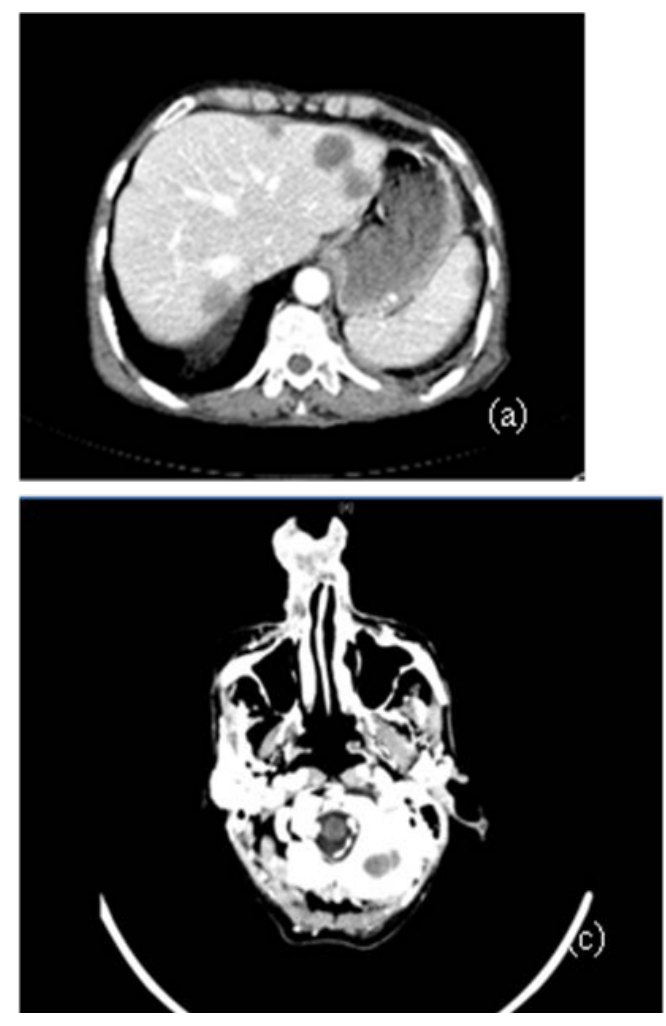

Figure 2. (a) CT scan abdomen showing liver and spleen metastasis; (b) CT scan chest showing left lung mass with mediatstinal metastasis; (c) \& (d) Horizontal and sagital sections CT scan facial bones showing the tumour.

The lesion was excised under general anaethesia with $1 \mathrm{~cm}$ safety margin and sent for histopathological examination which was reported as moderately differentiated sinonasal squamous cell carcinoma, basaloid type. There was involvement of the anterior and lateral margins with the tumour cells.

The case was discussed in the tumour board meeting and the plan of management was discussed with the patient and the relatives. Palliative chemotherapy in the form of 5-fluorouracil and carboplatin were started by the oncology doctors.

\section{Operative Procedures}

Further wide local excision was done under general anaesthesia and free margins were confirmed by frozen section examination. This resulted in amputation of most of the nose with loss of most of the alae on both sides, loss of most of the septum and loss of the upper and lower nasal cartilages. The nasal bone was exposed with no overlying skin. The nose of the patient was reconstructed by using a left nasolabial flap and forehead flap based on the right supratrochlear artery.

A nasolabial flap was raised from the left cheek $5 \mathrm{~cm}$ in length and inverted upside down to make the nasal lining. Deepithelisation of the flap at the site of suturing to the septum and both alae was done. The flap was sutured to each of these structures using 4/0 rapid Vicryl sutures. The donor area of the flap was closed in two layers. There became a resulting raw area formed of the nasal bone proximally, the under surface of the nasolabial flap and the caudal part of the exposed cartilage of the nasal septum (Figure 3). This raw area was covered with a forehead flap based on the right supratrochlear artery after designing it in the shape of the nose. The donor site of the forehead flap was directly closed. A small area at the middle was covered with a split thickness skin graft harvested from the medial aspect of the left arm. The rest of the skin graft was used to cover the proximal part of the nasolabial flap and the undersurface of the proximal part of the forehead flap (Figure 4).

The patient was kept on medications and dressings postoperatively. Both the flaps were found well viable and the grafts settled well. He was discharged from the hospital 2 weeks postoperatively. The patient was not reviewing the Plastic Surgery Clinic regularly. The follow up revealed a recurrent tumour starting to grow about 2 

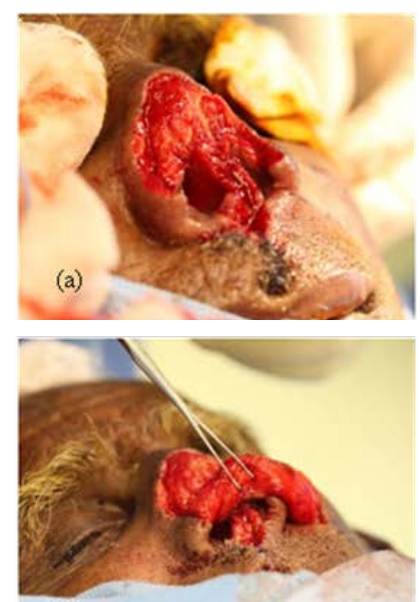

(d)
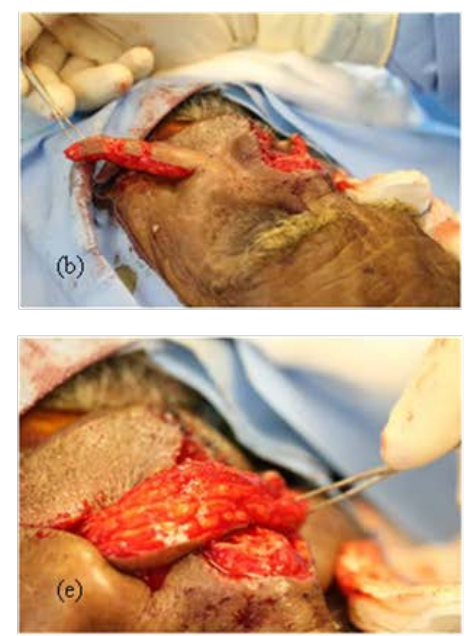
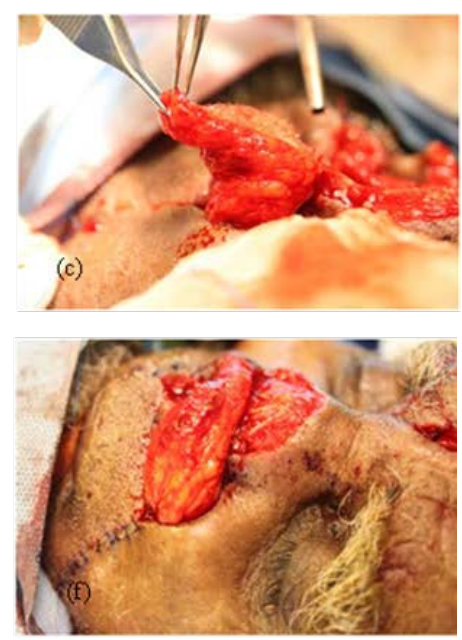

Figure 3. (a) The area to be constructed; (b) Left nasolabial flap elevated and deepithelialised at 3 areas; (c) The most medial deepithelialised area is sutured to the left ala; (d) The other two deepithelialised areas are sutured to the nasal septum and the right ala successively; (e) Starting closing the donor site of the flap in layers; (f) The nasolabial flap is viable and ready to be covered by the forehead flap.
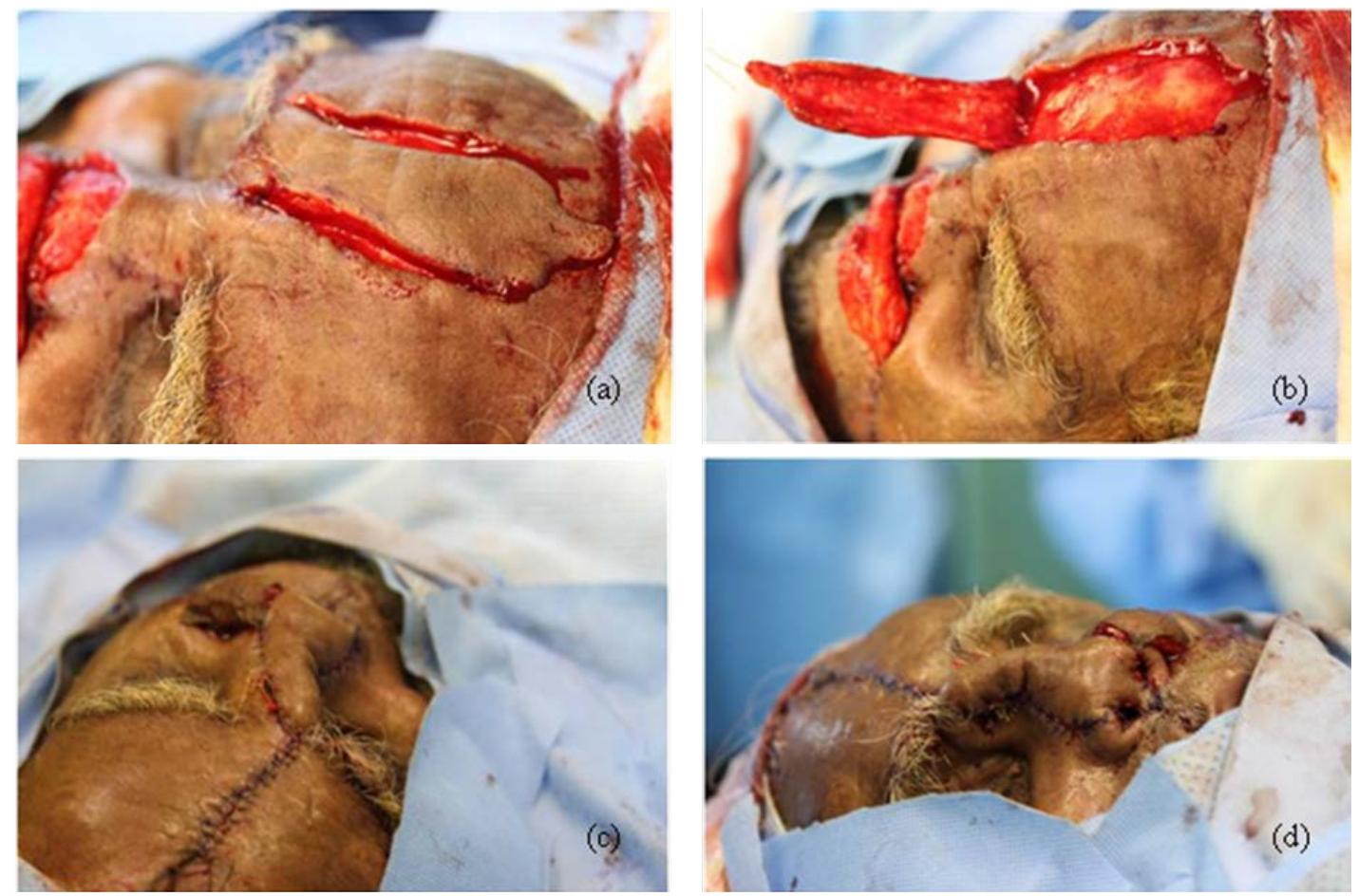

Figure 4. (a) The incisions for forehead flap; (b) The forehead flap raised; (c) The forehead flap inset; (d) At the end of surgery.

months postoperatively at the upper lip which was widely excised under general anaesthesia and sent for frozen section examination (Figure 5). The defect of the upper lip was covered with a fan flap with incorporation of Z-plasty flap. Division of the left nasolabial flap and the forehead flap was done at the same time (Figure 6 and Figure 7). The postoperative period was uneventful except that the patient was somewhat upset as he had to wait for his beard to grow back which is part of his tradition. The patient was discharged from the hospital 8 days postoperatively. He was on regular follow up in the Plastic Surgery and Oncology Clinic. He survived about 6 months postoperatively in a good acceptable shape without bad odour or disfigurement (Figure 8). 

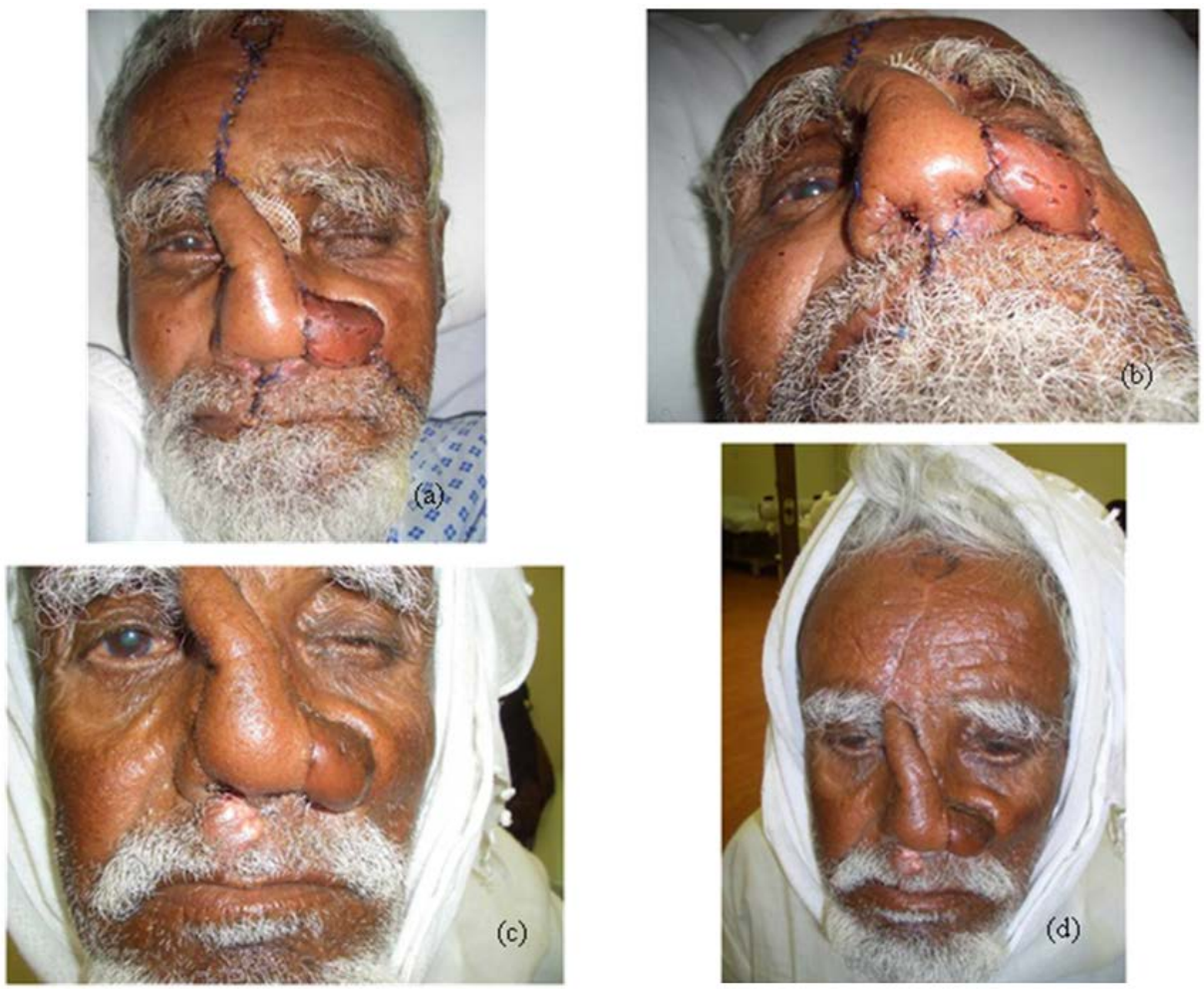

Figure 5. (a) Early post operative frontal view; (b) Early post operative nasal view; (c) Two months later with recurrence of the tumour at the upper lip; (d) Donor site of the forehead flap healed. Recurrence seen at the upper lip.
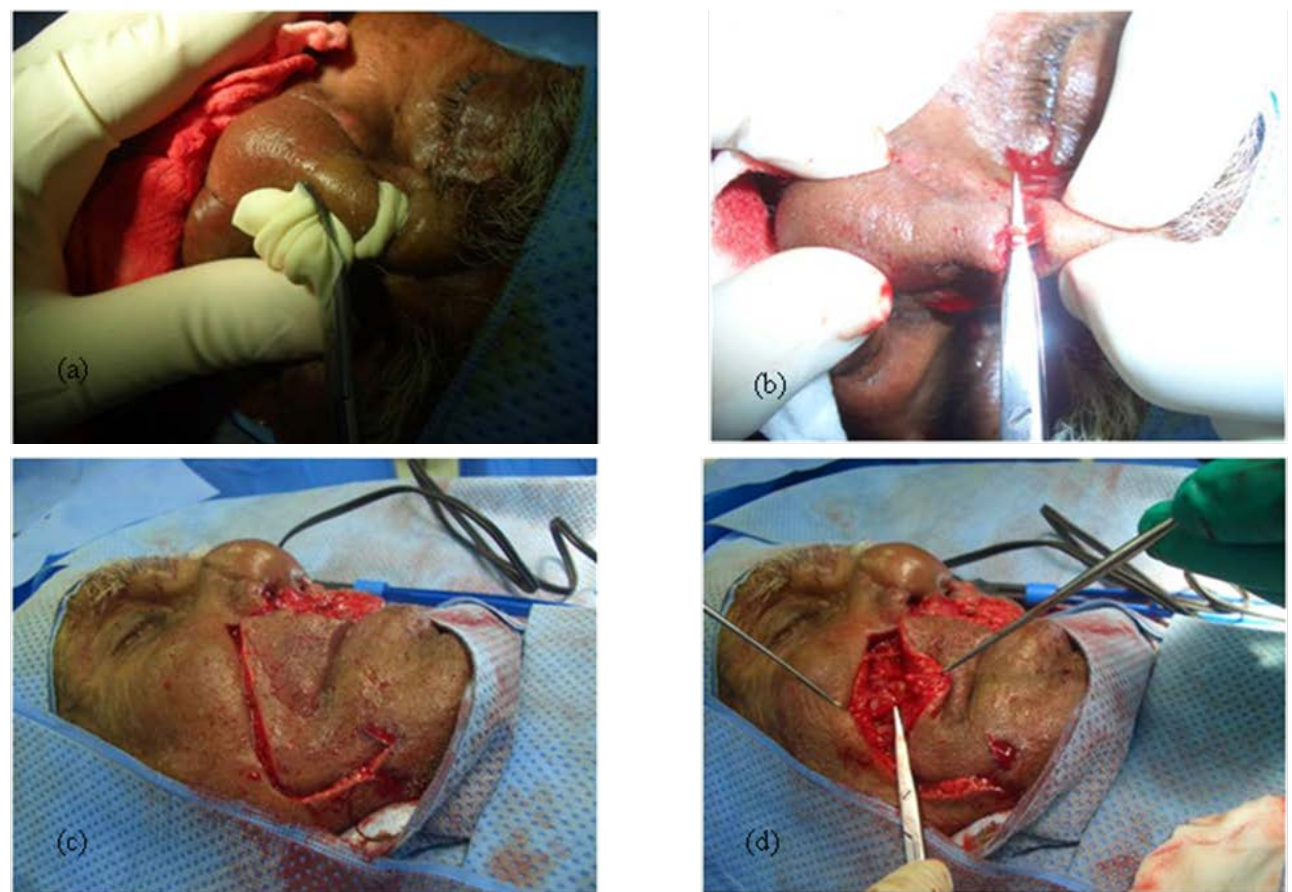

Figure 6. (a) Tourniquet applied at the pedicle of the forehead flap to confirm viability before division; (b) The Supratrochlear artery identified and cauterized. Pedicles for both flaps divided; (c) The tumour of the upper lip excised with safety margin. Incisions made for the fan flap; (d) Identification of the feeding vessels and branches of the facial nerve. 

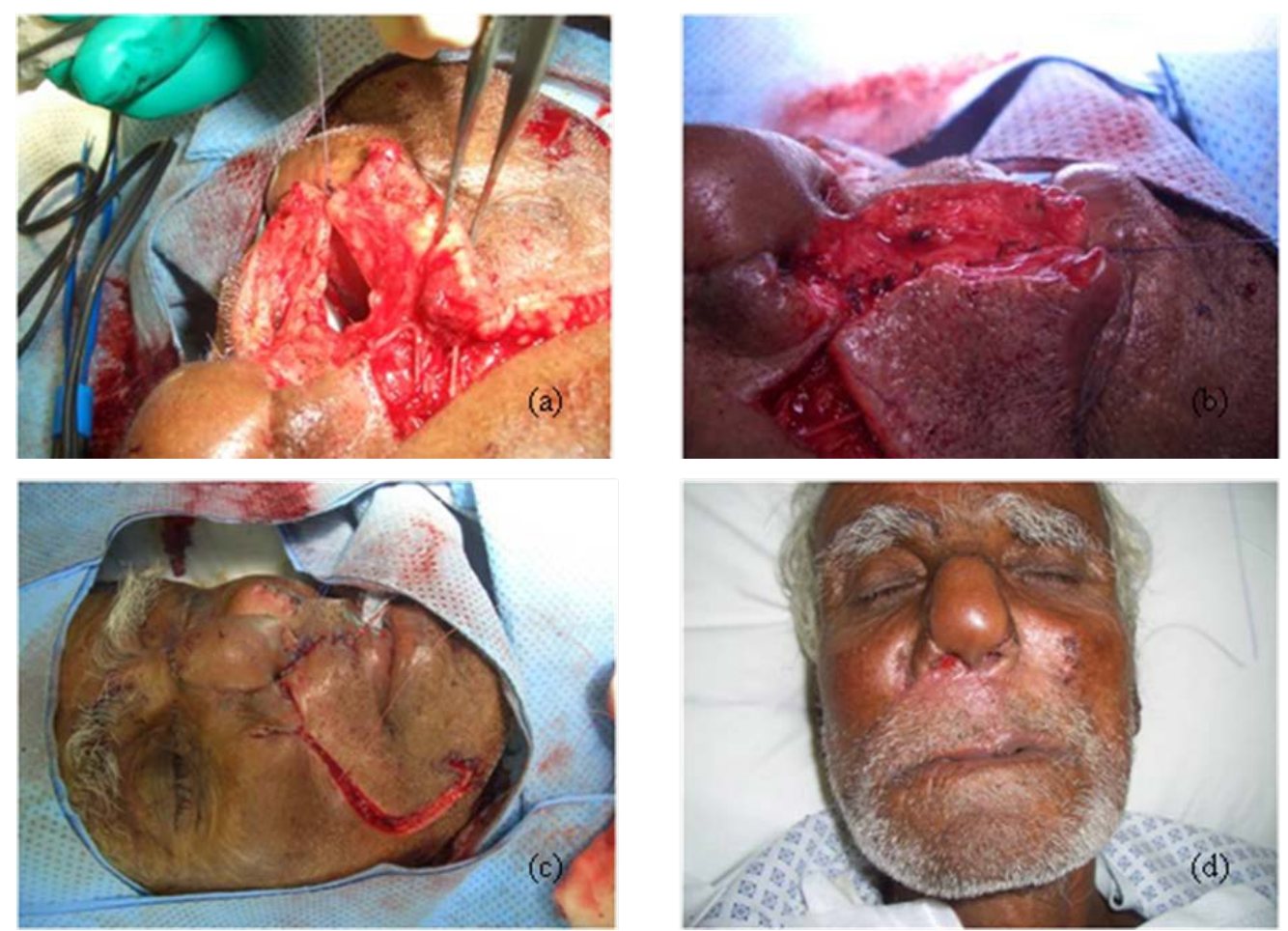

Figure 7. (a) Repair of the mucosa of the upper lip; (b) Flap mobilisation; (c) Suturing of the flap. The tubercle of the upper lip is also reconstructed; (d) Early postoperative result.
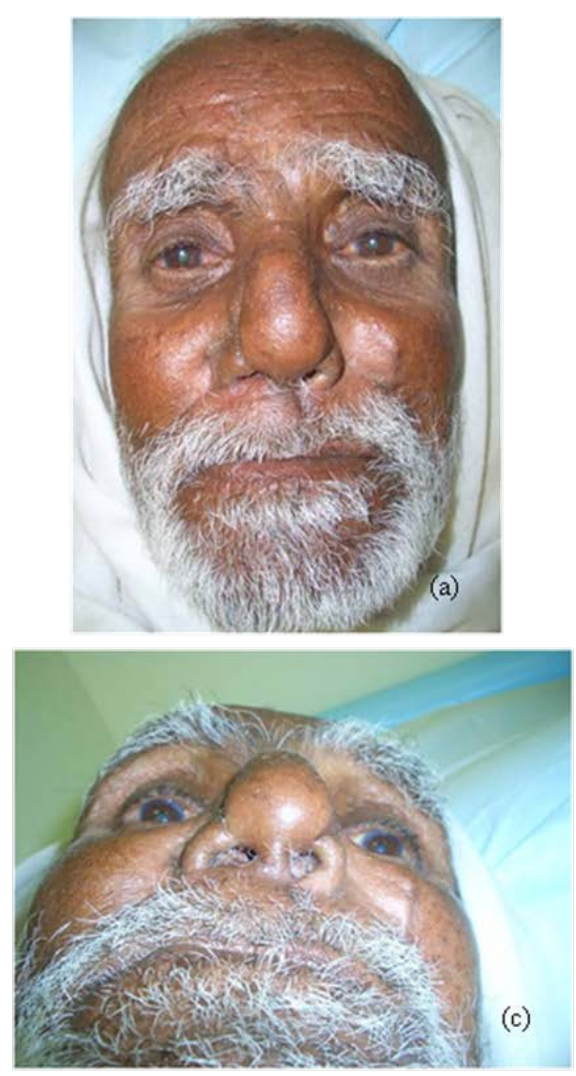
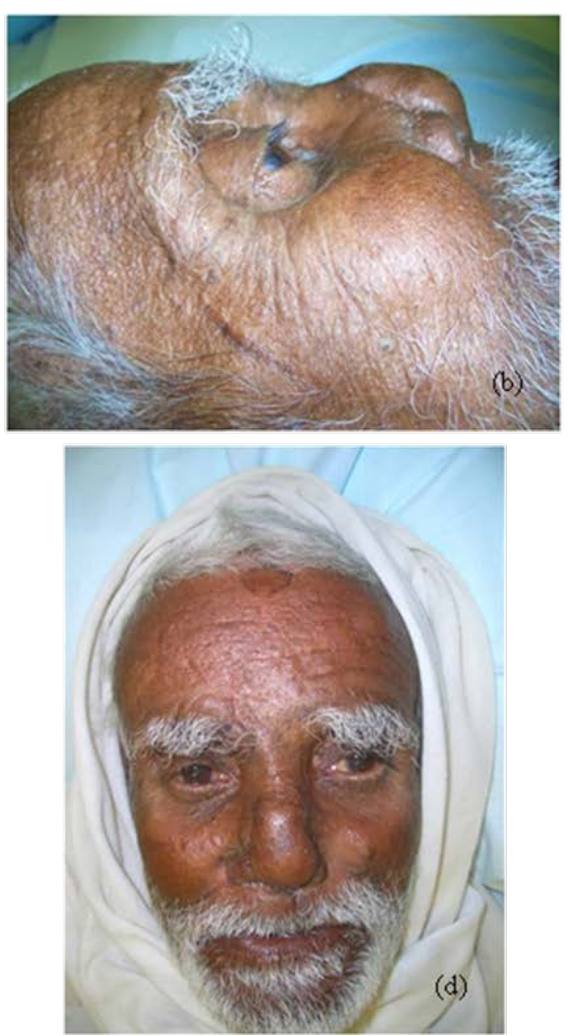

Figure 8. (a) Late postoperative frontal view; (b) Lateral view; (c) Nasal view; (d) Final shape. 


\section{Discussion}

The history of nasal surgery goes back to many centuries BC. Edwin Smith in 1862 discovered an Ancient Egyptian papyrus which is considered as the oldest known surgical treatise dated to the old kingdom from 3000 to 2500 BC. It included among its subjects surgery of the nose [1].

In ancient India, Sushrata used the forehead flap for nasal reconstruction about $700 \mathrm{BC}$ as amputation of the nose was a way of punishment at that time [2].

Till now the forehead flap is considered as the best option for nasal reconstruction due to its superb colour and texture match, vascularity and ability to resurface all or part of the nose [3]. The forehead flap is an axial flap based on the supratrochlear artery. The supratrochlear artery is found to consistently exit the superior medial orbit approximately 1.7 to $2.2 \mathrm{~cm}$ lateral to the midline, and continues its course vertically in a paramedian position approximately $2.0 \mathrm{~cm}$ lateral to the midline [4] [5].

The forehead flap surgery is usually done on two stages of flap inset and later on flap division. Some surgeons prefer to get it done on three stages by adding a stage of flap thinning in between which was not necessary in our case [6].

Ibrahimi et al. managed to construct the nose in a single stage using this flap by islandising it and passing it under a skin tunnel at the medial side of the eyebrow. In this way he avoided division of the flap in a second stage but using this technique the flap could only reach till above the tip of the nose [7]. This was not suitable for our case which required also columellar reconstruction.

Many procedures for nasal lining are described. The use of local nasal mucosal flaps was not possible due to loss of most of the nose.

Winslow et al. used free radial forearm fascial flap for the nasal lining and split calvarial bone and auricular cartilage to make frame for the nose [8]. Nasal frame reconstruction by using costal grafting, the use of 3-dimentional laser surface scanning and the use of titanium mesh or other alloplastic materials are all prescribed techniques [9]-[11].

In our case considering the general condition of the patient, the systemic metastasis and the short life span expectancy of the patient we felt that these sophisticated procedures may not be the best option for him and he can benefit, for the remaining months of his life, from a simpler technique with less morbidity. That is why we chose the nasolabial flap as a lining after deepithelialising 3 parts of it. The nasolabial flap was used before for nasal reconstruction either for coverage [12] or as a lining [13]. We found the flap to be well reliable and vascular. The flap was able to give coverage to both nostrils. The bulky subcutaneous fat of the flap gave the shape of the dome of the nose.

Fan flap described by Gillies is a useful technique for upper lip reconstruction [14]. In our case the flap was able to cover the defect resulted from excision of the tumour and it was well viable with acceptable appearance of the lip.

\section{Summary}

For advanced stages cancer nose, the use of complicated procedures of nasal reconstruction as cartilage or bone grafts may not be required. Providing an acceptable shape to the patient to face his community for the remaining period of his life using simpler techniques can be a good and satisfactory solution.

\section{Conflict of Interest}

The authors declare that they have no conflict of interest.

\section{Ethical Approval}

All procedures performed in this study involving human participant were in accordance with the international ethical standards.

\section{Informed Consent}

Additional informed consent was obtained from the participant for whom identifying information is included in this article. 


\section{References}

[1] Mazzola, I. (2012) Plastic Surgery: Principles. Elsevier Health Sciences, 11-12.

[2] Namdev, L.N. and Darbari, A. (2013) Nasal Reconstruction with Forehead Flap: Our Experience. Indian Journal of Otolaryngology and Head \& Neck Surgery, 65, 177-180. http://dx.doi.org/10.1007/s12070-013-0654-6

[3] Menick, F.J. (2007) Nasal Reconstruction. Grabb and Smith’s Plastic Surgery. 6th Edition, 389-396.

[4] Thakur, D.R., Mohindroo, N.K. and Sharma, D.R. (2010) Forehead Flap for Nasal Reconstruction. Clinical Rhinology: An International Journal, 3, 13-15. http://dx.doi.org/10.5005/jp-journals-10013-1019

[5] Boyd, C.M., Baker, S.R., Fader, D.J., Wang, T.S. and Johnson, T.M. (2000) The Forehead Flap for Nasal Reconstruction. Archives of Dermatology, 136, 1365-1370. http://dx.doi.org/10.1001/archderm.136.11.1365

[6] Ribuffo, D., Serratore, F., Cigna, E., Sorvillo, V., Guerra, M., Bucher, S. and Scuderi, N. (2012) Nasal Reconstruction with the Two Stages vs Three Stages Forehead Flap. A Three Centres Experience over Ten Years. European Review for Medical and Pharmacological Sciences, 16, 1866-1872.

[7] Ebrahimi, A., Motamedi, M.H.K., Nejadsarvari, N. and Koushki, E.S. (2012) Subcutaneous Forehead Island Flap for Nasal Reconstruction. Iranian Red Crescent Medical Journal, 14, 271-275.

[8] Winslow, C.P., Cook, T.A., Burke, A. and Wax, M.K. (2003) Total Nasal Reconstruction; Utility of the Free Radial Forearm Fascial Flap. Archives of Facial Plastic Surgery, 5, 159-163. http://dx.doi.org/10.1001/archfaci.5.2.159

[9] Li, Q.F., Weng, R., Gu, B., Liu, K., Shen, G.X., Xie, F. and Zheng, D.N. (2010) Anchor-Shaped Nasal Framework Designed for Total Nasal Reconstruction. Journal of Plastic, Reconstructive \& Aesthetic Surgery, 63, 954-962. http://dx.doi.org/10.1016/j.bjps.2009.05.005

[10] Byrne, P.J. and Garcia, J.R. (2007) Autogenous Nasal Tip Reconstruction of Complex Defects. A Structural Approach Employing Rapid Prototyping. Archives of Facial Plastic Surgery, 9, 358-364. http://dx.doi.org/10.1001/archfaci.9.5.358

[11] Rodriguez-Prieto, M.A., Alonso-Alonso, T. and Sanchez-Sambucety, P. (2009) Nasal Reconstruction with Titanium Mesh. Dermatologic Surgery, 35, 282-286. http://dx.doi.org/10.1111/j.1524-4725.2008.34425.x

[12] Irfanullah, Khan, A., Khan, N., Shah, S.A. and Tahmeedullah (2012) Indications and Outcome of Nasolabial Flap: Experience at a Plastic Surgical Facility. Annals of Pakistan Institute of Medical Sciences, 8, 168-171.

[13] Kline, R.M. (2004) Aesthetic Reconstruction of the Nose Following Skin Cancer. Clinics in Plastic Surgery, 31, 93111. http://dx.doi.org/10.1016/S0094-1298(03)00097-X

[14] Lesavoy, M.A. and Smith, A.D. (2006) Lower Third Face and Lip Reconstruction. Plastic Surgery, 3, 799-858. 
Scientific Research Publishing (SCIRP) is one of the largest Open Access journal publishers. It is currently publishing more than 200 open access, online, peer-reviewed journals covering a wide range of academic disciplines. SCIRP serves the worldwide academic communities and contributes to the progress and application of science with its publication.

Other selected journals from SCIRP are listed as below. Submit your manuscript to us via either submit@scirp.org or Online Submission Portal.
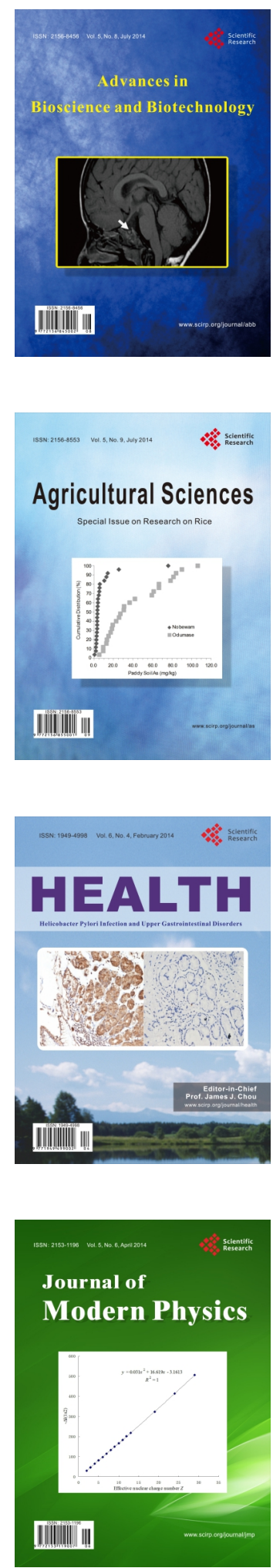
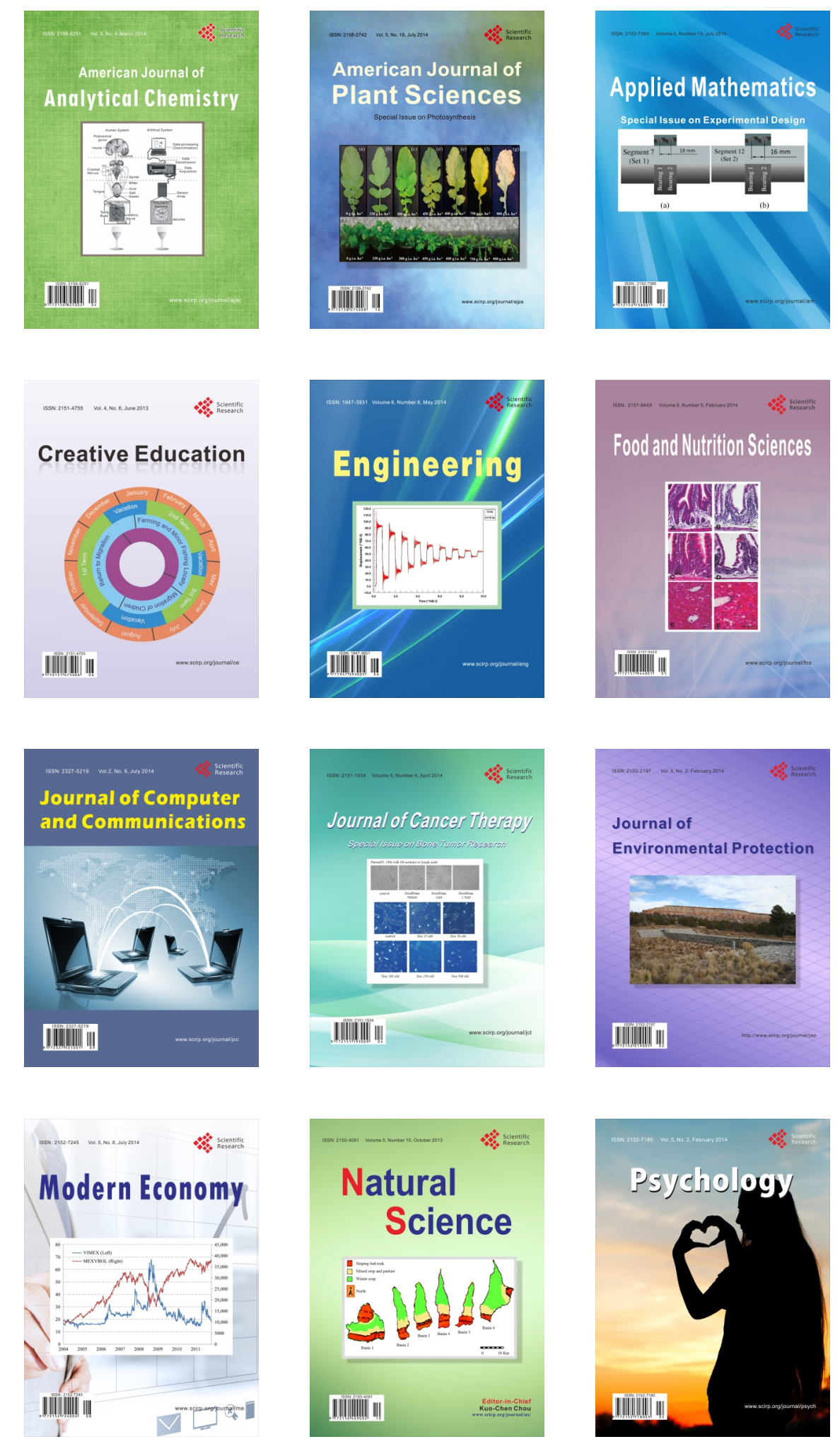